\title{
Fraseologia especializada do corte bovino
}

\author{
Specialized phrase of beef cutting
}

\author{
Rejane Umbelina Garcez Santos OLIVEIRA* \\ Universidade Federal do Pará (UFPA)
}

\begin{abstract}
RESUMO: Este artigo é um recorte do Dicionário Terminológico do Corte Bovino, produto da tese de doutorado intitulada Fraseologia do Corte Bovino: uma abordagem terminológica e terminográfica (OLIVEIRA, 2018) e objetiva destacar os principais tipos de fraseologias especializadas presentes no discurso oral e escrito da pecuária de corte bovino. $\mathrm{O}$ recorte teórico-metodológico segue a Socioterminologia, Variação terminológica e estudos fraseológicos especializados, a partir de Cabré (1999) e Mejri (1997, 2009, 2012). As fraseologias especializadas aqui em análise pertencem a dois dos quatro campos semânticos da pesquisa: ABATE e DESOSSA. Os resultados denotam sequências de curta e longa extensão, formadas ou não com um termo específico, mas, geralmente, constituídas por sintagmas nominais e suscetíveis às variações sintáticas, semânticas e pragmáticas, com níveis de fixação parcial, total ou extremamente cristalizadas pelo uso, as colocações. Isso evidencia a preferência que os profissionais têm pelas especificidades e convenções próprias da variedade linguística em que atuam.
\end{abstract}

PALAVRAS-CHAVE: Fraseologias especializadas. Sequências cristalizadas. Fraseologia do Corte Bovino.

ABSTRACT: This article is an excerpt from the Terminological Dictionary of Corte Bovino, product of the doctoral thesis entitled Phraseology of Corte Bovino: a terminological and terminographic approach (OLIVEIRA, 2018) and aims to highlight the main types of specialized phraseologies present in the oral and written discourse of livestock beef cattle. The theoretical-methodological approach follows Socioterminology, Terminological variation and specialized phraseological studies, from Cabré (1999) and Mejri (1997, 2009, 2012). The specialized phrases here under analysis belong to two of the four semantic fields of the research: ABATE and DESOSSA. The results denote sequences of short and long extension, formed or not with a specific term, but, generally, constituted by nominal phrases and susceptible to syntactic, semantic and pragmatic variations, with partial, total or extremely crystallized levels of use, the placements. This shows the preference that professionals have for the specificities and conventions of the linguistic variety in which they work.

KEYWORDS: Specialized phrases. Crystallized strings. Phraseology of the Bovine Cut.

\section{Introdução}

O contexto comunicacional determina o tipo de fraseologia a ser utilizada durante a produção de textos. Ela pode pertencer à língua geral, quando a nomeamos

\footnotetext{
${ }^{*}$ Doutora em Estudos Linguísticos pela Universidade Federal do Pará. Membro do Projeto GeoLinTerm, vinculado à Universidade Federal do Pará - UFPA. Belém, Pará. E-mail: rejane.garcez@gmail.com
} 
simplesmente como fraseologia, ou à língua de especialidade, podendo ser identificada como uma Unidade Fraseológica Especializada ou UFE. Ambas têm em comum a gramática e uma parte de seu inventário léxico-semântico que se compõe de morfemas, palavras, sintagmas e regras combinatórias.

Apesar da complexidade inerente ao tema, há muitos estudos sobre fraseologia e isso suscita uma variedade de nomenclaturas. Segundo Lara (2014), ao longo dos estudos foram diversas as denominações atribuídas como: Colocação, Combinação fixa de lexemas, Combinação lexical especializada, Coocorrente, Discurso repetido, Entidade fraseológica, Expressão fixa, Expressão idiomática, Expressão multilexêmica, Expressão pluriverbal, Frasema, Fraseologismo, Fraseotermo, Locução, ASP Phase, Sintagma fixo, Unidade complexa, Unidade fraseológica, Unidade fraseológica especializada e Unidade fraseológica especializada eventiva. Neste estudo, entretanto, usaremos a mesma terminologia adotada por Cabré, Lorente, Estopà, em 1996, Unidade fraseológica especializada ou, simplesmente, UFE.

Este artigo toma como base a tese de doutorado de Oliveira (2018), orientada pelo Professor Dr. Abdelhak Razky, da Universidade de Brasília e da Universidade Federal do Pará. Como produto dessa pesquisa, apresentou-se o Dicionário Terminológico do Corte Bovino, doravante, DTCB, organizado em quatro campos semânticos e composto por 1055 entradas, divididas entre termos e fraseologias especializadas. Entretanto, por questões metodológicas, esta comunicação se faz e limita-se a 110 das fraseologias que, entre muitas outras, abrangem os campos mais produtivos do estudo: ABATE e DESOSSA.

Pretende-se destacar que o léxico especializado praticado pelos atores da Cadeia produtiva do Corte Bovino - CPCB é formado por muitos termos, mas o que costura os discursos, sejam eles escritos ou orais, são as fraseologias que surgem nas comunicações formais ou informais, da cultura popular ou dos textos reguladores, fiscais ou quaisquer outros que se impõem na lida diária em uma sala de abate ou desossa em qualquer localidade, em qualquer abatedouro, frigorífico, supermercado ou feira. Essas Unidades Fraseológicas Especializadas - UFE's constituem o foco dessa comunicação, sua identificação e classificação daquelas mais produtivas no domínio da pecuária de corte. 


\section{Base teórico-metodológica}

Para Cabré (1993, 1999), as linguagens de especialidade apresentam variações porque possuem aspectos linguísticos e pragmáticos comuns, o que faz com que sejam consideradas subconjuntos da linguagem geral, pois têm certa unidade. Portanto, ao analisá-las, deve-se considerar, também, as suas dimensões cognitiva e social, pois é no discurso do usuário da língua que suas representações cognitivas do domínio de especialidade a que pertence, serão, pela linguagem, expressas. Ainda assim, para a pesquisadora, o estudo fraseológico segue a perspectiva terminológica que considera a UFE de base verbal, distinguindo-se, portanto, dos termos, mais frequentemente, de base nominal.

As linguagens especializadas fazem uso seletivo e criativo dos mesmos elementos que a fraseologia da língua geral faz e conseguem refletir as particularidades dos conceitos ou variações. No entanto, só a partir dos anos 90, a Terminologia aumentou consideravelmente o interesse pelas fraseologias especializadas devido à falta de produções textuais especializadas e de traduções científicas e técnicas.

O estudo da fraseologia especializada, no Brasil, é, relativamente, recente pois apesar de ter seu início na última década do século passado, pode contar com muitas contribuições resultantes dos estudos doutorais e pós-doutorais realizados por estudiosos da linguagem, entre os quais Maria Aparecida Barbosa, Maria do Socorro Silva de Aragão, Maria Tereza Biderman, Maria Helena de Moura Neves, Margarida Basílio, Ieda Maria Alves, Enilde Faulstich, Stela Ester Ortweiller Tagnin, Maria Luísa Ortíz Alvarez e Cláudia Maria Xatara.

Percebe-se hoje que além dos termos, há outras unidades linguísticas que veiculam no discurso especializado dando singularidade aos textos de determinados domínios. Por outro lado, foram inúmeras as definições formuladas na tentativa de se chegar a um consenso sobre o que seja a fraseologia especializada. Muito já se alcançou, mas ainda há o que se investigar pois existem divergências entre seus autores. Uma delas é referente à extensão que os termos ou sintagmas terminológicos e fraseologias especializados podem apresentar.

Alguns estudiosos, nas duas últimas décadas, dedicaram-se à fraseologia especializada por um viés teórico-prático impulsionados pelos estudos de Hausmann (1990) e Mel'cuk (1984; 1988; 1992). Trata-se de uma perspectiva mais ampla em que 
as colocações ou unidades fraseológicas são combinações sintagmáticas determinadas, principalmente pela(s): relação semântica entre seus elementos, suas estruturas morfossintáticas/frequência e pela perspectiva terminológica em que as unidades fraseológicas são unidades sintagmáticas, formadas por dois ou mais elementos e um deles é um termo (ou não). Esse termo identifica ou seleciona a unidade. A perspectiva terminológica possui uma visão mais restrita das unidades fraseológicas, pois as distingue, claramente, das unidades terminológicas sintagmáticas.

Cabré (1999, p. 138) ao falar sobre texto especializado, ressalta que sua principal função é "[...] informar ou trocar informações a respeito de um tema especializado". Ou melhor, para que se compreenda integralmente uma linguagem especializada é necessário que se tenha domínio sobre as fraseologias que nela se operam. Assim como as fraseologias do léxico geral, as especializadas também apresentam uma estrutura sintagmática em que seus significados só podem ser depreendidos a partir do conjunto formado por constituintes. Um texto só será considerado texto especializado se suas sequências sintagmáticas, a que nomeamos de UFE's, ao serem interpretadas, apresentem significados condizentes com seu entorno e com o domínio ao qual se referem.

Nesse âmbito, fraseologia especializada é uma unidade formada por dois ou mais constituintes e que apresenta combinações lexicais e gramaticais com estruturas recorrentes. Costumam ser estruturas de maior extensão, têm produtividade em textos especializados e no corte bovino, domínio em análise, estrutura-se como:

Termo + adjetivo [carne in natura]

Verbo + termo [tipificar a carcaça]

Termo + verbo [curral de observação / vaca reformada]

Subst. + prep. + art. + termo [trânsito das carcaças]

No léxico especializado do corte bovino, a partir dos pressupostos teóricos já mencionados, a identificação das UFE's se sobressai apesar de serem extremamente relevantes todas as contribuições sobre as fraseologias especializadas fornecidas pelos estudos já realizados, sabe-se que apenas os critérios linguísticos não são suficientes e, por esta razão, nesta investigação, segue-se os estudos efetuados por Mejri (1997), uma 
vez que apresenta critérios (testes morfossintáticos e semânticos) para o reconhecimento das fraseologias especializadas em função da cristalização que sofrem. Esses testes permitem avaliar se há alguma flexibilidade morfossintática e semântica nessas unidades e se é possível considerar que haja diferentes graus de cristalização no léxico especializado em questão.

O enfoque dado por Mejri (2009) é um pouco diferenciado, pois considera que o estudo da fraseologia de uma área de conhecimento pressupõe a compreensão entre fenômeno e processo. É fenômeno quando se realiza pelas associações sintagmáticas recorrentes. Essas associações, para se concretizarem, sofrem o processo de cristalização, o que é comum a todas as línguas vivas, independe da vontade dos falantes e, principalmente, é um aspecto sistêmico que atua na funcionalidade da língua possibilitando que cada sintagma possa ser uma unidade polilexicalizada.

Mejri (1997), ao definir fraseologia, considerou-a como um fenômeno que ocorre continuamente através de associações sintagmáticas recorrentes, e a fixação como o processo em que essas associações se realizam. Considera a fraseologia como um fenômeno recorrente em todos os níveis de análise linguística: morfossintático, semântico e pragmático. Segundo o teórico, a fraseologia é um excelente recurso do qual o usuário da língua poderá fazer uso em todas as situações e a fixidez explica as fraseologias e descreve a cristalização como decorrente do congelamento das regras de combinação sintagmática nos planos sintático, semântico e pragmático. Ele define, então, uma sequência fixa como:

C'est une notion nouvelle, forgée pour expliquer le phénomène phraséologique et décrire le processus du figement par lequel les solidarités syntagmatiques connaissent un blocage des règles de la combinatoire syntagmatique [...]. (MEJRI, 2012, p. 142-143). ${ }^{1}$

A fixidez é um dos traços mais relevantes apresentados no conjunto de características das fraseologias até agora estudados. Essas sequências cristalizadas, ao serem estudadas, alguns autores como Gross (1996), Anscombre (1983) e Mejri (1997) atribuíram-lhes o tratamento de sequences figées e, ao fenômeno, figement.

A fixação, como característica mais importante, implica relações com outras características como a polilexicalidade, idiomaticidade e convencionalidade.

\footnotetext{
1 “É uma noção nova, forjada para explicar o fenômeno fraseológico e descrever o processo da fixação pelo qual as solidariedades sintagmáticas sofrem um bloqueio das regras da combinatória sintagmática". (Tradução nossa).
} 
De acordo com o autor, ao se falar de fraseologias especializadas, deve-se reforçar o conceito sobre a fixidez (congelamento ou cristalização) que pode apresentar. Afinal, a cristalização presente no léxico geral também pode se apresentar no léxico especializado e, mais especificamente, a cristalização sintática de certas formas linguísticas opõem-se a outras formas livres na estrutura da língua.

Uma sequência cristalizada pode se apresentar com fixidez total ou parcial da combinação sintagmática e/ou da comutatividade paradigmática, como ocorre em serra fita (máquina usada em frigoríficos e grandes mercados para cortar peças de carne com osso) e curral de observação (onde ficam os animais que precisam de observação do veterinário antes de irem para o abate). Mas também podem apresentar fixidez parcial, quando a sequência atende a alguns ou todos os critérios a que é submetida para comprovar o seu grau de pertinência naquele campo especializado (carne moída > carne (muito) moída> carne (nova) (muito) moída.

Ainda segundo a concepção de Mejri (2006), as sequências cristalizadas são polilexicais, bem formadas e fixas o que possibilita a previsibilidade sintagmática fazendo com que as colocações especializadas possam surgir em decorrência das fortes restrições paradigmáticas encontradas no léxico especializado. Ao se observar quarto dianteiro, quarto traseiro, chã de dentro, chã de fora, fundação esquerda, mesa de inspeção, plataforma de evisceração, nota-se que são construções que ao se dizer o primeiro constituinte já vem à mente o segundo. Não há como separá-los e a existência de um já pressupõe o outro, estão fortemente atraídos como os ímãs se atraem. Não dependem da vontade do falante. Também são congruentes porque são formantes previsíveis de ocorrência no corte bovino.

Em relação à fixidez, Mejri (1997) ainda atribui a ela o crédito por explicar a fraseologia e descrever a cristalização, o que acaba por estabelecer uma diferença entre ambas. Por isso considera que a fixidez tenha graus diferentes. Uma sequência terá fixidez total quando ocorrer o congelamento das regras da combinação nos planos sintático, semântico e pragmático. Se a fixidez da combinação sintagmática e da comutatividade paradigmática for parcial, também será fraseologia.

As cristalizações podem ocorrer nas UFE's pelas restrições possíveis no eixo sintagmático, quando estas ocorrem pelas flexões, pronominalizações e passivização; e 
no eixo paradigmático quando a restrição ocorre durante a comutação dos termos e/ou inserção de novos constituintes na sequência.

A fixação é, portanto, característica essencial, mas não é suficiente para caracterizar uma UFE, porque, segundo o autor, as palavras compostas, como sacarolha, também passam pelas mesmas restrições, e, nem por isso, são unidades fraseológicas especializadas. O que lhes dá o caráter de especializada são as condições de ocorrência em determinado domínio.

\section{Fraseologias do corte bovino}

O léxico especializado do corte bovino é constituído por unidades especializadas de categorias diferenciadas: Unidades Terminológicas Simples (UTS's) e Unidades Terminológicas Complexas (UTC's) a que, inicialmente, chamou-se de sequências sintagmáticas, por serem constituídas de sintagmas, uma vez que agrupam dois ou mais vocábulos e a esse agrupamento (re) atribui-se um novo sentido.

Como dito anteriormente, esta comunicação apresenta 110 fraseologias que fazem parte do DTCB, composto por 1055 entradas, das quais, 665 são fraseologias especializadas. Percebeu-se no corpus que duas estruturas constroem o discurso nessa área de atividade: aquela construída a partir de um termo que corresponde a $65 \%$ das fraseologias especializadas constantes no dicionário e as compostas por unidades comuns à língua geral, 35\% delas, mas que ao serem concatenadas, atribuem um sentido específico no corte bovino.

\subsection{Fraseologias formadas a partir de um termo}

Entre tantos termos de alta frequência no corpus examinado, abate foi escolhido por ser um dos que melhor contempla os interesses de agora e as fraseologias selecionadas para compor um mostruário foram consideradas como especializadas porque têm uso recorrente e, pelo uso, foram institucionalizadas na área do corte bovino. 


\author{
abate clandestino \\ abate de emergência \\ abate de matrizes \\ abate humanitário \\ abate Kosher \\ área de abate \\ box de abate \\ deslocamento do abate
}

engorda para abate

estresse pré-abate

idade de abate

insensibilização para o abate

linha de abate

ritual de abate

ritual judaico de abate

Há, entretanto, muitas outras fraseologias especializadas na cadeia do corte bovino como picanha com maminha, ponta de agulha, toalete da carcaça, maquiagem da picanha, cabeça de lombo, chã de fora, chã de dentro, músculo de primeira, carne de primeira, músculo de segunda, carne de segunda, bife do vazio, coxão mole, coxão duro, miolo da paleta, bombom da paleta.

\subsection{Fraseologias que não se estruturam a partir de um termo}

As fraseologias que se apresentam no discurso dos profissionais que atuam no corte bovino são especializadas porque têm uso recorrente e foram, pelo uso, institucionalizadas nesse domínio.

\author{
avental de malha de aço \\ banho de aspersão \\ bomba recalque \\ calha de resíduos \\ câmara pulmão \\ carro cuba \\ chute de resíduos \\ chuveiro da seringa \\ corredor da morte \\ corte primário
}
decantador da linha verde
etiqueta testeira
forçador de frio
fundação esquerda
guia de trânsito de animal
lagarto paulista
máquina de arquear
máquina de serra fita
material específico de risco
primeiro transpasse 
O léxico especializado do corte bovino apresenta fraseologias que foram analisadas e descritas sob os parâmetros estabelecidos por Mejri (1997). Essas unidades sintagmáticas, para o autor, são polilexicais, mas também há outras que não apresentam as mesmas caraterísticas. Daí a distinção entre sequências sintagmáticas classificadas como fraseologias, e as sequências livres de que fala Mejri e no corte bovino podem ser representadas por frigorífico de abate, sala de abate, tecnologia do abate, entre outras.

Mejri (1997) em Le figement lexical: descriptions linguistiques et structuration sémantique analisa o processo de fixação (figement) que ocorre em verbos suporte, colocações, expressões idiomáticas, pragmatemas, locuções, provérbios, estereótipos e alerta em relação à noção de continuum que ocorre nas sequências fixas. Ele mostra que uma sequência livre pode passar a ser fixa e que isso ocorre de forma gradual, quase imperceptível. O uso contínuo, repetido, faz com que as regras sintagmáticas e pragmáticas se cristalizem, como ocorre com primeiro transpasse, filé mingnon ou bife do vazio. Esse congelamento independe da vontade do falante e não possibilita mais qualquer alteração na sequência, nem no eixo sintagmático.

As restrições em relação às flexões, pronominalizações e passivização pertencem ao eixo sintagmático; enquanto a restrição para comutação de termos e inserção de novos elementos ficam no eixo paradigmático. No léxico especializado do corte bovino, a fixidez se somada à (in) congruência, outro critério postulado por Mejri, permite que se estabeleça a diferença entre fraseologia e sequência sintagmática livre. Em curral de observação, rolete do couro, rolete de courear, as restrições no eixo sintagmático provocaram a cristalização das sequências de tal forma que elas só podem ser consideradas como sequências sintagmáticas livres.

Por este princípio, ainda em relação à fixidez, Mejri (2012) a classifica como sintagmática e paradigmática. No corpus de pesquisa, foram identificadas sequências que se enquadram no nível paradigmático e têm fixação total, ou melhor, não podem comutar os elementos da combinatória. Mas o corpus apontou também para sequências cuja cristalização ocorreu de forma parcial, em pelo menos dois níveis:

a) quando as variações possíveis não põem em dúvida o caráter cristalizado da sequência como em:

- abrir bucho, em que se pode flexionar o nome no diminutivo, abrir buchinho; 
- bovino de corte, ao ser flexionado o termo no plural, continua sendo congruente no sistema.

b) quando as variantes são transparentes, apresentam nuances semânticas em nível de sistema:

- abrir bucho, o verbo abrir se for substituído por arriar, por exemplo, continua congruente na língua (arriar bucho);

- paleta com osso pode ser substituída por braço, variante do termo paleta

.Segundo Mejri (2012), as sequências livres também são compostas por sintagmas, a diferença é que estas sequências não são polilexicais, enquanto aquelas são. Portanto, toda unidade fraseológica é polilexical, mas nem toda sequência polilexical é uma unidade fraseológica.

Para Mejri (2012), a polilexicalidade é mais um critério que ajuda a identificar uma fraseologia. Em se tratando de fraseologia especializada, esse estado de polilexicalidade pode ser uma característica distintiva entre as frases fixas ou cristalizadas das demais. As sequências sintagmáticas fixas no léxico do corte bovino são muito produtivas, caracterizam o discurso especializado e sua polilexicalidade, além de que a partir dela, identifica-se o grau de especialização do texto. Assim, percebem-se sequências comuns a discursos menos especializados e outras que compõem aqueles com maior grau de especialização, como se pode observar nos exemplos a seguir dispostos num continuum do menos especializado ao mais especializado.

\section{Menos especializadas}

boi ralado

caminhão frigorificado

corredor da morte

lava mão

toalete da carcaça

bananinha do contrafilé

trilho suspenso
$>>>>>$

>>>>>

$>>>>>$

$>>>>$

$>>>>>$

$>>>>>$

$>>>>>$
Mais especializadas

carne moída

caminhão frigorífico

brete de contenção

higienizador de mãos

limpeza da carcaça

músculo intercostal

nória elétrica

A polilexicalidade é uma propriedade presente no léxico do corte bovino e, a partir dela, pôde-se observar que de acordo com o nível sintático, a combinação aqui se 
limita ao mesmo nível da frase, entre os elementos da frase como em desossa da carcaça, embarcadouro de bovino, pistola de atordoamento, descola do matambre, chute de bucho condenado ou vaca reformada para abate desde que repasse o sentido da cadeia de palavras e não o sentido de cada uma delas.

A segmentação utilizada na industrialização do corte bovino em campos e subcampos semânticos leva a relações hierárquicas entre as diferentes etapas do processo de ABATE e DESOSSA, principalmente. A polilexicalidade possibilitou no corpus essa relação paradigmática. A partir dessa compreensão, foi possível, por exemplo, a observação do uso de hipônimos ou hiperônimos de acordo com o grau de especialização da comunicação que se desejava imprimir ao discurso. Ao se indicar na etiqueta da bandeja o termo agulha (hiperônimo), induz-se ao raciocínio de que se trata apenas de um tipo de corte bovino. Entretanto, se o alvo é um consumidor com um pouco mais de conhecimento sobre cortes bovinos ou mais familiarizado com os cortes efetuados em sua comunidade, é possível que se particularize mais ainda esse tipo de corte, indicando na etiqueta se é agulha com osso ou agulha sem osso (hipônimos).

Nesta pesquisa o estudo da fraseologia considera os critérios de identificação e classificação adotados por Salah Mejri (2009). O teórico afirma que há alguns critérios que podem ser aplicados para o reconhecimento e classificação dos fraseologismos. Mejri apoiou-se na tipologia preconizada por G. Gross (1996) e M. Gross (1996) que classificou as sequências cristalizadas por partes do discurso.

Para melhor clareza, segue uma exemplificação da aplicação desses testes, ao se retomar o exemplo anteriormente citado. Sob a análise proposta por Mejri, em alguns casos como toalete da carcaça, carne sifada, carne nobre e abate humanitário ocorrem estruturações possíveis, isto é, nessas estruturas há a possibilidade de se fazer reestruturações que conduzem ao grau de fixidez que essas sequências podem apresentar. Por exemplo: Carne maturada apresenta um subst. + adjetivo. Esta estrutura admite além da posposição do adjetivo, a coordenação ou agrupamento de adjetivos: carne macia e maturada. Carne maturada e macia; permite que o advérbio provoque modificação: carne muito maturada, carne especialmente maturada; e ainda aceita modificadores preposicionais: carne maturada de nelore. Logo, é uma sequência sintagmática que se classifica como uma fraseologia. 
Durante este fenômeno pode ocorrer o congelamento das regras de combinação sintagmática nos planos sintático e semântico como em filé mignon, por exemplo. Mejri (1997) indica, como instrumentos metodológicos para se chegar a uma descrição e funcionamento da linguagem de especialidade, a fixidez e a congruência. Segundo ele, bastam esses dois critérios para a identificação de uma fraseologia.

A título de exemplificação, tomou-se uma fraseologia comum nesse léxico de especialidade para a aplicação dos testes: carne morta:

a) Posposição do adjetivo:

Carne morta + moída

Subst. $\quad$ Adj.

b) Coordenação ou agrupamento dos adjetivos:

Carne morta + barata.

Subst. Adj.

Carne morta + novinha + e barata.

Subst. Adj . Adj.

Carne morta + fresquinha.

Subst. Adj.

c) Modificação pelos advérbios:

Carne morta + muito cara.

Subst. Adv.

Carne morta + bastante moída.

Subst. Adv.

d) Acréscimo de adjetivos pospostos ou de modificadores preposicionais:

Carne + morta + de gado.

Subst. Adj. Modificador preposicional

Carne + morta + especial

Subst. Adj.

Adj. 
Após a aplicação dos testes chegou-se à tipologia das unidades especializadas que co-ocorrem com maior frequência nesse léxico de especialidade: sequências cristalizadas e semicristalizadas, além de colocações especializadas provenientes das fortes restrições paradigmáticas nesse léxico de especialidade.

A seguir apresenta-se uma amostra de algumas fraseologias referentes ao corte bovino, classificadas e distribuídas em semicristalizadas, cristalizadas e colocações:

a) semicristalizadas, correspondem a $56 \%$ das fraseologias especializadas encontradas. São 372 UFE's de um total de 665 que constituem entrada no DTCB. Seguem alguns exemplos: abate bovino, abate humanitário, agulha redonda, amarrinho do esôfago, bisteca desossada, vaca reformada para abate, carro de transporte de miúdos sequestrados, carne maturada, carne moída, carne nobre, carne comum, costela fina, boi ralado, carne morta.

b) cristalizadas, correspondem a apenas $21 \%$ do total. Em média são 140 fraseologias. A seguir, as de maior produtividade: produção de carne macia, cabeça de lombo, filé mingnon, toalete da carcaça, bife do vazio, primeiro transpasse, lavagem da carcaça, bife do vazio, etiqueta testeira.

c) colocações, são $23 \%$ do total das fraseologias especializadas. Alguns exemplos: quarto dianteiro, quarto traseiro, chã de dentro, chã de fora, bastão elétrico, arriar bucho, linha de abate, mesa de inspeção dos mocotós, box de abate, calha de resíduos, gerador de água quente, linha de abate.

As categorizações das UFE's extraídas do corpus são apresentadas a seguir, no Gráfico 1, de acordo com seus respectivos percentuais. Aquelas que nos testes apresentaram fixidez parcial, admitindo as regras sintagmáticas (ou parte delas) assim como a comutatividade paradigmática, quando expostas aos testes foram consideradas do ponto de vista da idiomaticidade mais transparentes. 


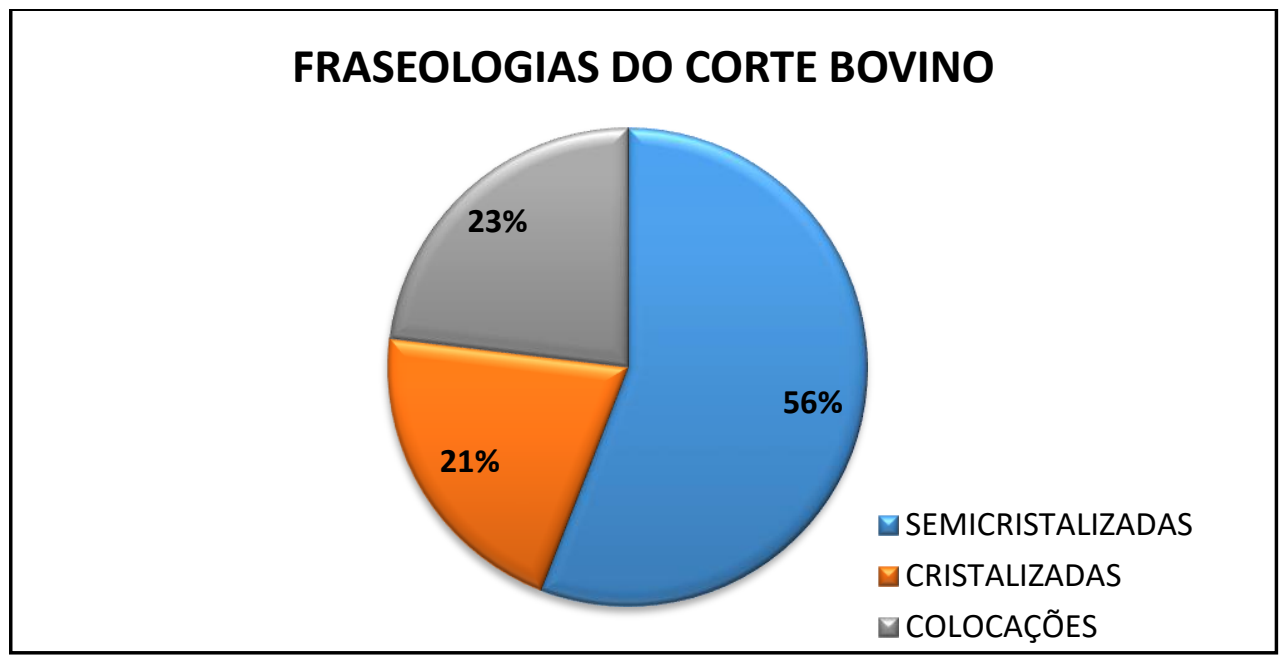

Fonte: Oliveira (2017, p. 172)

Já as sequências cristalizadas apresentam-se em número mais reduzido e constituem formas opacas, porque sofreram o congelamento de suas regras de combinação sintagmática nos planos sintático, semântico e pragmático, de tal forma que não foi possível ajustá-las aos testes aplicados. Apresentam fixação total e quanto maior o grau de fixação que apresentarem, maior será a opacidade delas. Coxão mole e coxão duro são nomes de cortes que o uso consagrou, quando se fala em coxão, no âmbito do corte bovino, já se sabe que ou é mole ou é duro. Portanto, o uso cristalizou essas formas nesse léxico de especialidade. Se trocar alguma coisa, muda o sentido.

O mesmo ocorre com filé mignon, um corte muito apreciado da musculatura bovina, mas que tem sua forma cristalizada como filé mignon. A cristalização no corte bovino também decorre do fato desse léxico especializado ser altamente técnico, o que faz com que o nível denotativo esteja presente em todos os constituintes da fraseologia e o uso já tê-las consagrado nos textos especializados desse domínio.

Quanto às fraseologias tipificadas por Mejri (2012) como colocações, neste estudo representam a minoria. Em princípio, considerou-se que nas linguagens especializadas todos os instrumentos são termos técnicos e, por isso, deveriam ser classificados como colocações. Entretanto, ao serem testadas e analisadas as ocorrências, percebeu-se que as colocações são compostas por estruturas muito próximas, mas tão próximas que se atraem. Funcionam como ímãs e pertencem ao conjunto das unidades fraseológicas. Apresentam restrições paradigmáticas fortes. Nos exemplos, ao se falar de fundação esquerda (referência à lateral esquerda do traseiro do 
boi), a dissociação dos elementos que compõem o sintagma constitui uma incongruência porque fere o critério pragmático. $\mathrm{O}$ mesmo ocorre com quarto dianteiro e quarto traseiro em que os elementos decompostos ferem esse critério.

As fraseologias classificadas como colocações têm no corte bovino alto grau de cristalização, a ponto de serem consideradas como unidades estáveis e serem préfabricadas no sistema da língua.

De acordo com os modelos fraseológicos mais usuais, estudados por Mejri, na terminologia do corte bovino a unidade fraseológica surge como hiperônimo que denomina o objeto de estudo da fraseologia especializada, podendo abranger vários tipos de combinações, desde as compostas por duas palavras até aquelas que constituem frases inteiras, tendo sempre, como característica principal, a polilexicalidade e a fixidez.

Constata-se que de acordo com Cabré (1999), o autor do discurso técnico e científico, como qualquer outro usuário da língua portuguesa, constrói, através da linguagem, representações mentais da realidade. Para a autora é no discurso que as suas representações cognitivas de seu domínio de especialidade tomam forma. Se o discurso não pode ser dissociado do social, a natureza social que ele tem se evidencia pela presença do outro, parceiro da comunicação, com quem o locutor divide o espaço discursivo, tendo por finalidade convencê-lo e ocupar o lugar principal como autoridade discursiva, através da prática linguística, sujeita às normas aceitas pelos usuários da linguagem de especialidade.

\section{Considerações Finais}

Neste artigo, procura-se comunicar que as fraseologias especializadas que compõem o domínio da pecuária de corte corroboram a teoria de que esse léxico é também composto por fraseologias especializadas para referenciar coisas e conceitos nessa área de atividade; que a nomeação dessas coisas se dá por meio de variantes as quais nem sempre são transparentes a todos os envolvidos na CPCB e que em consequência disso, o discurso, seja ele oral ou escrito, sofre variações relativas aos aspectos sintático, semântico e pragmático.

Apresentou-se os principais tipos de fraseologias especializadas que ocorrem nesse discurso especializado, abrangendo especificamente a DESOSSA e o ABATE, 
campos semânticos mais produtivos para o surgimento delas, de acordo com as pesquisas realizadas por Oliveira (2018) e que foram a base deste artigo.

Do corpus examinado, das 665 fraseologias que compõem o DTCB (OLIVEIRA, 2018), 622 apresentaram o substantivo como a categoria gramatical com maior representatividade. Apesar de haver sintagmas verbais e raras construções adjetivas e adverbiais, são os sintagmas de base nominal que predominam, pois constituem $59 \%$ desse léxico especializado.

Como a linguística não é o suficiente para explicá-las, pois seu uso em um ou outro discurso também depende de uma escolha, de uma preferência condicionada ao "modo de dizer" utilizado em uma ou outra localidade pela qual o falante tenha preferência, tomou-se a teoria de Salah Mejri, Le figement lexical, para identificá-las e hierarquicamente distribuí-las em semicristalizadas, cristalizadas e colocações.

Se, como tão bem afirma Faulstich (1995), as línguas são heterogêneas, são um sistema plural e nelas há normas que destacam seus usos reais em variação, é imprescindível que o especialista do corte bovino não só domine o conhecimento científico ou técnico da área, mas se aproprie também de terminologia específica da área em que atua, seja científica ou não, e esse domínio envolve além dos termos, as unidades fraseológicas daquela linguagem de especialidade e as variantes que coocorrem nos textos e discursos orais e escritos desse ramo de especialidade.

Especificamente, esta apresentação poderá incitar a todos que se interessarem pelas pesquisas fraseológicas realizadas na área da pecuária de corte bovino; possibilitará uma visão mais abrangente desse léxico de especialidade como parte da língua geral e, portanto, sujeito às variações próprias a qualquer língua. 


\section{REFERÊNCIAS}

ANSCOMBRE, J-C.; DUCROT, O.. L' argumentation dans la langue. Bruxelles: Mardaga, 1983.

CABRÉ, Maria Teresa. La terminología: representación y comunicación - elementos para una teoría de base comunicativa y outros artículos. Barcelona: Institut Universitaride Lingüística Aplicada, 1999.

CABRÉ, Maria Teresa; LORENTE, Mercè; ESTOPÀ, Rosa. Terminología y fraseología. Actas del V Simposio de Terminología Iberoamericana, Ciudad de México, nov. 1996.

CABRÉ, Maria Teresa. La terminología: teoría, metodología, aplicaciones. Barcelona: Antártida, 1993.

FAULSTICH, Enilde. Base metodológica para pesquisa em Socioterminologia: termo e variação. Brasília: Centro Lexterm, 1995.

GROSS, G. Les expressions igées en français, noms composés et autres locutions. Paris: Ophrys, 1996.

GROSS, M. Les nominalisations d'expressions figées. Langue Française, Paris, Larousse, n. 69, p. 64-84, 1996.

HAUSMANN, F. J. Le dictionnaire de collocations. In: HAUSMANN, F. J. et al. An International encyclopedia of lexicography. Berlin; New York: Walter de Gruyter, 1990. p. 1010-1019. v. 1.

LARA, M. L. G. Diferenças conceituais sobre termos e definições e implicações na organização da linguagem documentária. Ciência da Informação, v. 33, n. 2, p. 91-96, 2004.

LARA, M. S. Variação das Unidades Fraseoterminológicas da Culinária entre PB e PE, 2014 - Tese de doutoramento em Linguística. Faculdade de Ciências Sociais e Humanas - FCHS: Departamento de Linguística. RUN - Repositório Universidade Nova . Disponível em: https://run.unl.pt/handle/10362/6448.

MEL'CUK, I. et al. Dictionnaire explicatif et combinatoire du français contemporain. Recherches léxico-sémantiques I, II, III, University ofmontreal Press, Montreal. 1984, 1988, 1992. 
MEJRI, S. Le figement lexical: descriptions linguistiques et structuration sémantique. Manouba: Publications de la Faculté des Lettres de la Manouba, 1997.

MEJRI, S. Phraséologie et traduction des textes spécialisés, La phraséologie contrastive: Figement et traduction, corpus et traitement des données, P. Mogorron Huerta (dir.), Université d'Alicante (sous presse), 2009.

MEJRI, S. Délimitation des unités phraséologiques. In: ORTÍZ-ALVAREZ, M. L. (org.). Tendências atuais na pesquisa descritiva e aplicada em fraseologia e paremiologia. Campinas, SP: Pontes, 2012.

MEJRI, S. Polylexicalité, monolexicalité et double articulation: la problématique du mot. Cahiers de lexicologie, v. 2, n. 89, p. 209-221, 2006.

OLIVEIRA, R. U. G. S. de. A terminologia do corte bovino: uma abordagem terminológica e terminográfica. Tese de doutorado em Estudos Linguísticos Universidade Federal do Pará, Belém, Pará, 2018. 